\title{
An Empirical Study on the Influence of Service Fairness on Logistics Customer Satisfaction: Based on the Intermediary Effect of Customer Psychological Empowerment
}

\author{
Jiahua WEI, Yi LIAN \\ School of Management, Guilin University of Technology, Guilin, China
}

\begin{abstract}
In this paper, take the logistics industry as an example, take the customer psychological empowerment as an intermediary, studied the influence of service fairness on customer satisfaction. The research results show that: the four variables under the authorization of service fairness has significant positive influence on customer psychology empowerment; customer psychological empowerment on customer satisfaction has significant positive impact; customer psychological empowerment between service fairness and customer satisfaction plays an intermediary role. This paper will study the customer psychological empowerment into the customer satisfaction, expand the research in the field of vision
\end{abstract}

KEYWORD: Logistics; Service Fair; Logistics Customer Satisfaction; Hypothesis Testing

Logistics industry is an important part of the service industry, and plays an important role in the modern economy. The monthly publication of the Chinese logistics industry boom index (LPI) From China Federation of Logistics and Purchasing is not only an important index measuring the running status of the logistics industry, but also to measure the running status of Chinese macroeconomic weather vanes. Therefore, through the promotion of logistics customer satisfaction, not only can enhance the competitiveness of the logistics industry, and also has an important significance for the development of global economy.

In Chinese and foreign literature, research on logistics customer satisfaction of logistics industry has been more, but to customer psychological empowerment as the perspective is not. But in the logistics service, customer psychological empowerment is the objective existence, so the research on customer psychological empowerment in the logistics service function, it is very necessary to analyze customer behavior. At the same time, this paper to study the logistics customer satisfaction by introducing the concept of customer psychological empowerment which belongs to the research field of psychology, can not only expand the study of logistics services, and more in depth analysis of the formation mechanism of logistics customer satisfaction, provide a reference for the logistics enterprises and efficient service.

\section{LITERATURE REVIEW AND HYPOTHESIS}

\subsection{Service fairness and customer psychological empowerment}

Tax takesuccess of services recovery actions are divided into three aspects: distributive fairness, procedural fairness and interactive fairness. Goodwin explains the service recovery logistics customer satisfaction from procedural fairness and interactive fairness[1]. Bies separated from the concept of procedure fairness and put forward the concept of "contact fairness"[2]. The customer service personnel often according to honesty, courtesy and preferences to assess interactive justice. Some researchers also studied the information fairness. Such as Xie Lishan, Zimmerman, Warschausk etc.. Integrated the previous analysis, this paper select the procedure fairness, results fairness, interactional fairness and information fairness evaluate the service fairness. The present study on customer empowerment has two kind of perspective. One is how to customers empower of enterprises, it focuses on the study of the behavior of empower of enterprises to customers. As Gabriel think that the customers empower is granted the ability of enterprise customers exercising freedom of choice behavior. Raman proposed that the enterprise use empower as a strategy, to give customers the right to speak and the right to choose, to improve the enterprise marketing ability. Another perspective on customer empower is the impact of customer 
empowerment behavior measures in enterprises, subjective change their psychological aspects of perception, i.e. customer psychological empowerment. Some of the current Chinese and foreign literature for customer authorization definition, and is often on the definition of customer psychological empowerment. Thomas pointed out that customer psychological empowerment has four dimensions: meaning, self-efficacy, self decision and the influence of. The Chinese scholar Han Xiaoyun etal proposed customer psychological empowerment dimensions including influence, right. Based on the above analysis, put forward the following hypothesis:

H1: Procedural fairness has significant positive impacts on customer psychological empowerment.

$\mathrm{H} 2$ : Result fairness has significant positive impacts on customer psychological empowerment.

H3: Interactive fairness has significant positive effect on customer psychological empowerment.

$\mathrm{H} 4$ : Information fairness has significant positive effect on customer psychological empowerment.

\subsection{Customer psychological empowerment and logistics customer satisfaction}

Cardozo in 1965 take logistics customer satisfaction first applied to the category of management science, many scholars explored further. The definition of logistics customer satisfaction includes two perspectives. That particular perspective of logistics customer satisfaction, logistics customer satisfaction is a customer in a specific situation, after consumer products or services obtained the value degree and make an instant mood reflects [3]; overall view of logistics customer satisfaction believe that logistics customer satisfaction is formed by a customer attitude, reflect after customer consumption degree of love, is a kind of to experience based holistic attitude, as the cumulative type satisfaction, is can directly evaluate the overall feel of ${ }^{[4]}$. In this paper, the definition of logistics customer satisfaction with the overall perspective, this has better dependability and stability. When the control feelings of customer perceived to enhance, customer psychological empowerment to enhance logistics customer satisfaction. Han Xiaoyun through empirical analysis that customer psychological empowerment has a direct positive effects on logistics customer satisfaction. At the same time, customer psychological empowerment played a mediating role in the effect of logistics customer satisfaction and service fairness of 4 variables. Therefore put forward the following hypothesis:

H5: Customer psychological empowerment has significant positive effect on logistics customer satisfaction.
H6: Customer psychological empowerment played a mediating role in effect relationship that procedure fairness, result fairness, interactional fairness, information fairness and logistics customer satisfaction.

\section{QUESTIONNAIRE DESIGN AND DATA COLLECTION}

\subsection{Questionnaire design and scale purification}

Based on the research hypothesis and design the questionnaire. The questionnaire consists of 6 variables, including 4 variables and 1 dependent variables. Independent variables as procedural fairness, interactive fairness, results fairness, information fairness; intermediary variables is customer psychological empowerment; dependent variables is logistics customer satisfaction. The researchers set 4-6 items in each variable through the literature references and interviews, total of item 31 . The questionnaire measurement used Likert 5 point scale.

In order to improve content validity of the questionnaire, the researcher invited 4 experts and 6 logistics customer with bachelor degree or above, deleted 4 inappropriate items, and 6 items were perfect. In addition, the researchers selected 52 logistics customer of Guilin city and Yangshuo city conducted a questionnaire survey (pretest), and use SPSS20.0 on the questionnaire were purified. The purified results show, there is a correlation between the project and the overall 2 items is less than 0.4, while the project after deleting 's a Cronbach where the variable coefficient will increase; there are 3 items in the rotated factors, the load is less than 0.4. Therefore according to the purification of Nunnally and Hair[5], delete these 5 items, the formal questionnaire composed of 22 items.

\subsection{Formal research}

The formal questionnaire generated, researchers in Guilin city and 4 county logistics of Guilin City, customer survey was conducted from September 27, 2013 to October 4th, 2013. Investigators including researcher and 4 undergraduates of Guilin University of Technology. Investigation object selection of this investigation are China Post, Yuantong express, general logistics, Guangxi quick. Investigators in each company's entrance or the station and other places, method of intercept investigation using the questionnaire survey on logistics customer, and guide customers to fill out the questionnaire to logistics. In the investigation, refused customers are more general because busy or research interest is not high. The survey questionnaires were distributed 405 , not returned questionnaires is 47 , and rejecting 
unqualified questionnaire (including incomplete questionnaire and answer questionnaire before and after the conflict etc.) is 66 , the recovery of 292 valid questionnaires, the return rate of effective questionnaire is 0.721 .

\section{THE ANALYSIS OF RESEARCH DATA}

\subsection{Reliability and validity}

The researchers used SPSS20.0 and AMOS20.0 for analysis of reliability and validity analysis, show the Cronbach 's alpha of 7 variables is greater than 0.7 , meet the reliability requirements, the reliability of the questionnaire through the test.

Content validity of the questionnaire. Because in the questionnaire development process, the researchers invited 4 experts and 6 with bachelor degree or above in logistics customer discussion and review of the questionnaire, deleted 4 inappropriate items, and 6 items were improved; at the same time, the questionnaire after pretest and purification, eliminating undesirable the questionnaire items, so the content validity by testing. According to the convergent validity test: the questionnaire of the items of the standardized factor loading greater than 0.50 and significantly; composite reliability (CR) values greater than 0.70 ; the average extraction variance (AVE) greater than $0.50^{[5]}$. As shown in Table 1, the composite reliability of 7 variables of the questionnaire (CR) values are greater than 0.70 , the average extraction variance (AVE) values are greater than 0.50 , and is significant, so the convergent validity questionnaire through the test.

\subsection{The hypothesis testing}

\subsubsection{Regression analysis}

The researchers take procedure fairness, result fairness, interactional fairness, information fairness as independent variable, customer psychological empowerment as the dependent variables to make the regression analysis. The standardized regression coefficient of procedure fairness, result fairness, interactional fairness, information fairness on customer psychological empowerment between 0.391 to 0.625 , and the $\mathrm{T}$ is greater than 1.96 , a significant level of SIG were less than 0.05 , the proof procedure fair of 4 variables on customer psychological empowerment has positive significant effects. Therefore the analysis results verify the prior assumptions, $\mathrm{H} 1, \mathrm{H} 2, \mathrm{H} 3, \mathrm{H} 4$.

At the same time, the researchers take customer psychological empowerment as independent variable, logistics customer satisfaction as the dependent variables to make the regression analysis. As shown in Table 3, the standardization of customer psychological empowerment on logistics customer satisfaction regression coefficient is 0.671 , and $t$ is 3.97 , more than 1.96 , a significant level of SIG is less than 0.05 , prove that customer psychological empowerment on logistics customer satisfaction has significant positive influence relationship. Therefore assume H5 passed the test.

\subsection{The analysis of the intermediary}

The analysis of the intermediary of reference Baron method for analysis of intermediary role[6], the researchers divided three steps for analysis of intermediary role to customer psychological empowerment, as shown in table 1. First of all, to verify the independent variables (procedure fairness, result fairness, interactional fairness, information fairness) on the dependent variable (logistics customer satisfaction) effect, shows the model1 authorized intermediary role between customer psychological satisfaction, regression coefficients of procedural fairness and other 3 variables on the logistics customer satisfaction was respectively $0.392,0.357,0.339,0.324$, and significant is 0.01 , show 4 variables have a significant effect on logistics customer satisfaction. Secondly, to verify the independent variables influencing the intermediary variable. The regression relation that procedure fairness, result fairness, interactional fairness, information fairness and customer psychological empowerment in the above analysis has been done, 4 variables on the customer psychological empowerment have a significant effect, namely argument generation significant impact on the intermediary variable. Thirdly, to control the intermediate variable of the independent variables on the dependent variable, to verify whether the effect disappeared (not significant) or decreases obviously. As shown in Table1, model2, Model3, model4, Model5, when the control of the intermediary variables, procedural fairness and interactional fairness can not significantly influence logistics customer satisfaction, the result fairness and information fairness although significant at the 0.01 level, but the effect was significantly reduced, in line with the intermediary variable inspection requirements. Therefore, assuming H6 through testing, customer psychological empowerment is the intermediary variables that 4 independent variables and logistics customer satisfaction (dependent variable). 
Table1 The analysis of the intermediary of customer psychological empowerment

\begin{tabular}{|c|c|c|c|c|c|c|}
\hline \multirow[t]{3}{*}{ Intermediary variables, } & Intermediary variables & \multicolumn{5}{|c|}{ Dependent } \\
\hline & $\begin{array}{l}\text { Customer psychological } \\
\text { empowerment }\end{array}$ & \multicolumn{5}{|c|}{ Logistics customer satisfaction } \\
\hline & & Model1 & Model2 & Model3 & Model4 & Model5 \\
\hline Procedure Result & $0.501^{* *}$ & $0.392^{*}$ & 0.121 & & & \\
\hline Result fairness & $0.439^{*}$ & $0.357^{*}$ & & $0.077^{*}$ & & \\
\hline Interactional fairness & $0.452^{*}$ & $0.339^{*}$ & & & 0.127 & \\
\hline Information fairness & $0.391^{* *}$ & $0.324^{* *}$ & & & & $0.053^{*}$ \\
\hline
\end{tabular}

\section{REFERENCES}

[1] Goodwin C, R oss I. Salient Dimensions of Perceived Fairness in Resolution of Service Complaints. Journal of Consumer Satisfaction, Dissatisfaction and Complaining Behavior. 1992, 12(2): 87 - 92.

[2] Bies R J, Moag J S. Interactional Justice: Communication Criteria of Fairness. Lewick RJ Sheppard B H, Bazerrman M H. Research on Negotiation in Organizations. Greenwich, Conn : JAI press: 43-45

[3] Woodruff, R. B., Ernest, R. C. Jenkins.R.L.. Modeling Consumer Satisfaction Processes Using Experience Based
Norms, Journal of Marketing Research, 1983, 20(3): 297304.

[4] Woodside, A.G., Frey, L.L. Daly, R.T.. Linking Service Quality, Logistics customer satisfaction and Behavioral Intention, Journal of Health Care Marketing, 1989, 9(1):817.

[5] NunnallyJ.C., Bemstein, 1.H.Psyehometrie Theory. 3rded.NY:MeGraw-Hill, 1994

[6] Baron, R. M. and D. A. Kenny. The moderator-mediator variable distinction in social psychological research: Conceptual, strategic, and statistical considerations. Journal of personality and social psychology, 1986, 51 (6): 1173. 